\title{
Lipoprotein(a) - Link between Atherogenesis and Thrombosis
}

\section{Danica Labudovic, Irena Kostovska, Katerina Tosheska Trajkovska, Svetlana Cekovska, Julijana Brezovska Kavrakova, Sonja Topuzovska} Department of Medical and Experimental Biochemistry, Faculty of Medicine, Ss. Cyril and Methodius University in Skopje, Skopje, North Macedonia Received April 23, 2019; Accepted September 4, 2019.

Key words: Lp(a) - Atherogenicity - Thrombogenicity - Cardiovascular disease Abstract: Lipoprotein(a) - $L p(a)$ - is an independent risk factor for cardiovascular disease (CVD). Indeed, individuals with plasma concentrations of $L p(a)>200 \mathrm{mg} / \mathrm{l}$ carry an increased risk of developing CVD. Circulating levels of $L p(a)$ are remarkably resistant to common lipid lowering therapies, currently available treatment for reduction of $L p(a)$ is plasma apheresis, which is costly and labour intensive. The $\mathrm{Lp}$ (a) molecule is composed of two parts: LDL/apoB-100 core and glycoprotein, apolipoprotein(a) - Apo(a), both of them can interact with components of the coagulation cascade, inflammatory pathways and blood vessel cells (smooth muscle cells and endothelial cells). Therefore, it is very important to determine the molecular pathways by which $\operatorname{Lp}(\mathrm{a})$ affect the vascular system in order to design therapeutics for targeting the $L p(a)$ cellular effects. This paper summarises the cellular effects and molecular mechanisms by which $L p(a)$ participate in atherogenesis, thrombogenesis, inflammation and development of cardiovascular diseases.

Mailing Address: Irena Kostovska, MD., PhD., Bul “Treta Makedonska Brigada” 31b/14, 1000 Skopje, North Macedonia; Phone: +389 782089 90; e-mail: irenakostovska22@yahoo.com 


\section{Introduction}

Since its discovery by Kare Berg in 1963, lipoprotein(a) - Lp(a) molecule, has been the subject of controversy and debate about its physiological role and role in atherogenesis, thrombogenesis and development of cardiovascular diseases (CVD). The exact physiological function of $L_{p}(a)$ has not been fully elucidated, however in recent years a number of prospective epidemiological and clinical studies have shown that Lp(a) level elevated more than $300 \mathrm{mg} / \mathrm{l}$ is an independent risk factor for development of coronary and cerebral atherosclerosis and powerful predictor of premature cardiovascular diseases in people with concomitant hypercholesterolemia. The European Society of Cardiology and European Atherosclerosis Society propose that $L p(a)$ should be measured once in subjects with intermediate or high risk of CVD such as: subjects with premature CVD, subjects with familial hypercholesterolaemia, a family history of premature CVD and/or elevated $L p(a)$, subjects with recurrent CVD despite statin treatment, subjects with $\geq 3 \% 10$-year risk of fatal CVD according to the European Guidelines (Graham et al., 2007; Catapano et al., 2016) and subjects with $\geq 10 \% 10$-year risk of fatal and/or non-fatal CVD according to the US Guidelines (Grundy et al., 2004). They also suggest that the risk is significant when $L p(a)$ levels are $>500 \mathrm{mg} / \mathrm{I}$ for European populations. It is emphasized that this threshold is higher than the risk threshold in primary care populations of $>200$ to $300 \mathrm{mg} / \mathrm{I}$ (Nordestgaard et al., 2010). The Canadian Cardiovascular Society Guidelines for the Management of Dyslipidemia for the Prevention of Cardiovascular Disease in the adult had similar recommendations, but they used a cut-off of $L_{p}(a)>300 \mathrm{mg} / \mathrm{l}$ as an abnormal level (Anderson et al., 2016).

Elevated Lp(a) carry an increased risk of occlusive complications following various cardiac interventions (percutaneous transluminal coronary angioplasty, stenting) (Berg, 1963; Danesh et al., 2000; Rifai et al., 2004; Nordestgaard and Langsted, 2016).

The concentration of $L p(a)$ levels is genetically determined and shows great individual and racial differences but inter-individually is stable throughout life. Elevated levels of $L p(a)$ are remarkably resistant to common lipid lowering therapies and dietary measures, currently available treatment for reduction of $L p(a)$ is plasma apheresis, which is costly and labour intensive (Moriarty and Hemphill, 2016; van Capelleveen et al., 2016; Khan et al., 2017). Thus, it is necessary to carefully clarify the physiological role of $L p(a)$ in the body and pathophysiological role of $L p(a)$ in the development of atherosclerosis and thrombogenesis in order to design therapeutic modality to reduce the concentration of $L p(a)$ levels in people with high risk of cardiovascular disease (Kronenberg, 1996a; Lippi and Targher, 2012; Boffa and Koschinsky, 2016; Tsimikas, 2017). In this paper are presented the structure and metabolism of $L p(a)$ and also are summarized recent literature data on cellular effects and molecular mechanisms by which $L p(a)$ participate in atherogenesis, thrombogenesis, inflammation and development of cardiovascular diseases. 


\section{Structure and metabolism of $\operatorname{Lp}(a)$}

$L p(a)$ molecule is expressed in humans, some primates (rhesus monkeys, baboons), and the European hedgehog (Amer. Barbed pig). Lp(a) is a complex and a unique lipoprotein particle rich in cholesterol. It is constructed from two components of low density lipoproteins (LDL) and apolipoprotein(a) - Apo(a). Apo(a) is structurally unique high glycosylated macromolecule whose size is genetically determined and highly variable. Apo(a) has determined structural and functional characteristics of Lp(a). Apo(a) is linked with a disulphide bond to ApoB-100 of LDL, building Lp(a). Stoichiometric ratio of Apo(a) and ApoB-100 in $L p(a)$ particle is 1:1. In Figure 1 is presented the structure of $L p(a)$.

$\mathrm{Lp}(\mathrm{a})$ and $\mathrm{LDL}$ are very similar in composition and physico-chemical characteristics. Table 1 shows the differences in physic-chemical characteristics and composition between Lp(a) and LDL.

Apo(a) gene is located on the long arm of chromosome 6 and several alleles, resulting in extensive polymorphism in individual expression. Gene Apo(a) is located adjacent to the gene encoding the synthesis of plasminogen which shows high structural similarity; it is assumed that the Apo(a) is a member of the plasminogen gene superfamily (Malgaretti et al., 1992). Apo(a) cDNA contains Kringle domains, autonomous protein domains rich in cysteine, which muster in tangles and are stabilized by disulphide bonds. They are important in protein-protein interactions in the process of blood coagulation. These domains have plasminogen, hepatocyte growth factor, prothrombin and Apo(a). Variations in the number of these domains are responsible for the size polymorphism in the molecular weight of $\operatorname{Lp}(\mathrm{a})$. Apo(a)

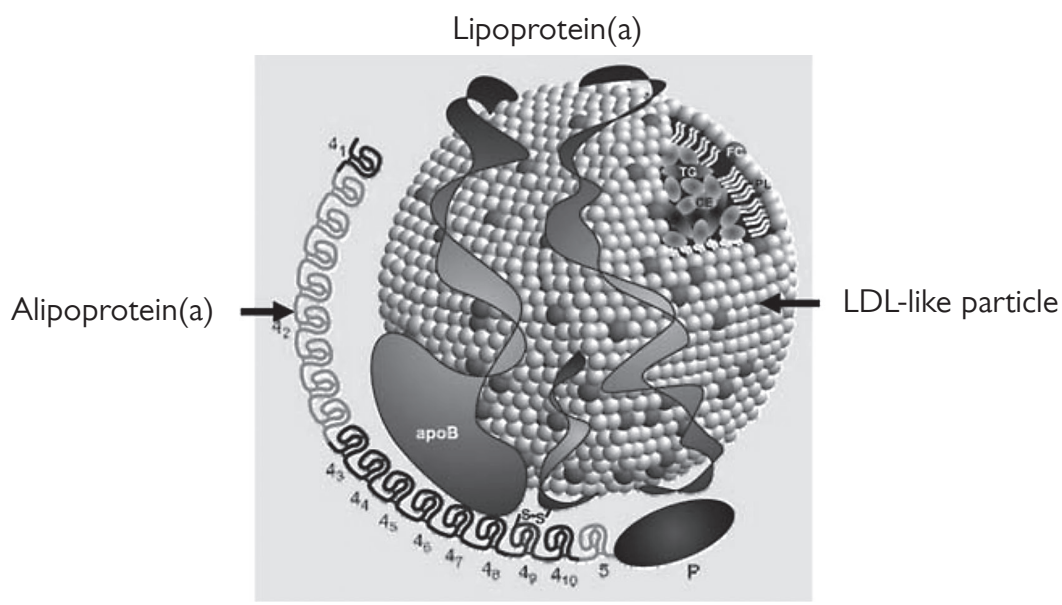

Figure 1 - Structure of lipoprotein(a) - Lp(a). Lp(a) contains low density lipoproteins (LDL) particle connected with apolipoprotein $(a)-A p o(a)$ - with disulphide bridge. LDL is built from a central core rich in cholesterol esters and triglycerides surrounded by phospholipids, free cholesterol and a molecule apolipoproteinB-100 - ApoB-100 (Bdeir et al., 1999). 


\section{Table 1 - Differences in physic-chemical characteristics and composition between Lp(a) and LDL}

\begin{tabular}{lcc}
\hline & Lp $(\mathrm{a})$ & $\mathrm{LDL}$ \\
\hline Electrophoretic mobility & $\mathrm{pre}-\beta$ & $\beta$ \\
Molecular mass $(\mathrm{kDa})$ & $800-1300$ & 549 \\
Density $(\mathrm{g} / \mathrm{ml})$ & 1069 & 1045 \\
Proteins \% & 30.0 & 22.5 \\
Carbohydrates \% & 4.5 & 1.0 \\
Cholesterol esters \% & 35.3 & 43.0 \\
Triglycerides \% & 2.0 & 3.0 \\
Free cholesterol \% & 8.5 & 11.0 \\
Phospholipids \% & 19.5 & 19.5 \\
\hline
\end{tabular}

Lp(a) - lipoprotein(a); LDL - low density lipoproteins

cDNA contains inactive serine protease domain, a copy of plasminogen Kringle $\mathrm{V}$ domain, and 10 types Kringle IV domains labelled Kringle IV-(1-10). Kringle IV-1 and Kringle IV-(3-10) are single domain while Kringle IV-2 is responsible for multiple domain size polymorphisms in the molecular weight of Apo(a) (300-800 kDa). Kringle IV-9 domain of Apo(a) has a specific binding site for ApoB-100 of LDL, found that it is associated with cell proliferation and smooth-muscle migration. Kringle IV-(6-7) domains mediate formation of foam cells in atherosclerosis, KIV-(7-8) domains are rich in lysine binding sites, Kringle IV-10 is responsible for the increased vascular permeability. cDNA contains the plasminogen Kringle domains I to $\mathrm{V}$, and the active form of serine protease domain, which is connecting with tissue plasminogen activator and urokinase plasminogen activator. This serine protease domain plays a key role in endogenous fibrinolysis (McLean et al., 1987). Principal place of synthesis of $L p(a)$ is liver. Association of Apo(a) with LDL in Lp(a) probably happens on the surface of hepatocytes. The synthesis of $L p(a)$ is carried out in two steps. First step is approaching sulfhydryl groups of Apo(a) and ApoB-100 and the second step is binding of Cys4057 of Apo(a) (Kringle domains IV-9) with Cys4326 of ApoB-100 by disulphide bond. The first step is inhibited by lysine and lysine analogues, such as lysine analogue tranexamic acid (Cyclocapron) which reduces the concentration of Lp(a) levels in humans (Frank et al., 1995). Binding of Apo(a), ApoB-100 occurs in the vicinity of the binding site of ApoB-100 on LDL receptor, which leads to poor affinity of $L p(a)$ the LDL receptor.

Catabolism of $L p(a)$ is not fully studied. $L p(a)$ has a longer half-life in plasma compared with LDL, suggesting that catabolism of Lp(a) does not take place entirely via the LDL receptor, but that there are other metabolic pathways for degradation of $\operatorname{Lp}(\mathrm{a})$, as through LDL receptor protein - megalin gp330, VLDL (very low density lipoprotein) receptor, galactose specific asialoglycoprotein receptor (ASGPR), plasminogen receptor and by macrophage receptors (Hrzenjak et al., 2003). 
The liver and kidney are the major tissues involved in $L p(a)$ clearance, but the pathways for $L p(a)$ uptake are still under investigation. Biochemical studies have revealed an exceptional array of receptors that associate with $L p(a)$ either via its ApoB, Apo(a), or oxidized phospholipids (OxPL) components, such as: namely "classical" lipoprotein receptors, toll-like and scavenger receptors, lectins, and plasminogen receptors. The importance of these receptors in catabolism of $L p(a)$ from the circulation are still unclear. The LPA gene encoding Apo(a) has an exceeding effect on $L p(a)$ levels which avert any clear associations between potential $L p(a)$ receptor genes and $\mathrm{LP}(\mathrm{a})$ levels in population studies. Targeted approaches and selection of unique $L p(a)$ phenotypes within populations has normally allowed for some associations to be made. Few of the suggested $L p(a)$ receptors can specifically be manipulated with current drugs, but it is not clear whether any of these receptors could provide relevant targets for therapeutic manipulation of $L p(a)$ levels (McCormick and Schneider, 2019).

Evidence indicated that $L p(a)$ is not a metabolic product of other lipoproteins, VLDL or LDL, nor is it metabolized to other lipoproteins. A few studies suggested that the variations in $\mathrm{Lp}(\mathrm{a})$ plasma concentration in individuals with different isoforms was due to the production rate of $A p o(a)$ rather than by its clearance rate. The low-density lipoprotein receptor (LDLR) was considered to be a possible site for the uptake and degradation of $L p(a)$, however reports are controversial regarding the significance of the role of the LDLR in Lp(a) catabolism (Kraft et al., 2000), which reported that for $L p(a)$ with the same allele size the concentration is dependent on the gene dose of the LDLR in familial hypercholesterolemia and deficient subjects have higher values of plasma $L p(a)$ than heterozygous subjects. However, kinetic studies suggested that the clearance of $L p(a)$ is not entirely dependent on the LDLR (Reyes-Soffer et al., 2017). LDL from $L p(a)$ is cleared by the LDLR only after release of Apo(a). It is reported that LDLR or low-density lipoprotein receptor-related protein (LRP) deficient fibroblasts did not alter their uptake and degradation of $L p(a)$ (Reblin et al., 1997). Although Lp(a) may bind to LDLR and LRP, the binding does not seem to be important for its degradation.

The fact that patients with nephrotic syndrome and chronic renal insufficiency have elevated concentrations of $\operatorname{Lp}(a)$, indicate the involvement of the kidney in the catabolism of Lp(a) (Kronenberg et al., 1996b; Schmidt et al., 2016). In one study was observed more Lp(a) deposition in the radial arteries of ESRD (end stage renal disease) patients with high Lp(a) concentration. Filipin and HE (hematoxylin and eosin) staining showed that cholesterol accumulation and foam cell formation are significantly higher in the group with high $\operatorname{Lp}(\mathrm{a})$ concentration than in the control group. These findings suggest that high plasma $L p(a)$ levels might be the main cause of cholesterol accumulation and foam cell formation in the radial arteries of ESRD patients (Ma et al., 2018). As we know, hypercholesterolemia is a main risk factor for the progression of atherosclerosis. Lipoprotein(a), one of the components of plasma lipid profile, was shown similar effects with hypercholesterolemia on promoting 
systemic atherosclerosis. Therefore, high-Lp(a) induced radial atherosclerosis means that $L p(a)$ may contribute to the progression of cardiovascular disease in ESRD patients.

\section{Concentration of $\operatorname{Lp}(\mathrm{a})$}

The concentration of $\mathrm{LP}(\mathrm{a})$ among individuals is genetically determined, shows large variations, ranging from 1 to $1,000 \mathrm{mg} / \mathrm{l}$, but remains stable throughout life (Puckey and Knight, 1999). There are variations in the concentration of $L p(a)$ levels between races due to the existence of polymorphisms in the sequence of Apo(a) isoforms and a lot of additional factors.

Polymorphisms of the Apo(a) gene regulates the concentration of $L p(a)$ levels by several mechanisms size polymorphism of Apo(a), through a number of iterations in pentanucleotide promoter region of $A p o(a)$ gene and over $93 \mathrm{C} / \mathrm{T}$ polymorphisms in non-transcribed region of $A p o(a)$ gene. There is an inverse correlation between the molecular weight of $L p(a)$, the number of Kringle IV domains in the Apo(a), and individual plasma concentrations of $\operatorname{Lp}(\mathrm{a})$. Thus, individuals with high molecular phenotypes of $L p(a)$ have low concentrations of Lp(a) plasma and those with high molecular phenotypes have high concentrations of $\mathrm{Lp}(\mathrm{a})$ plasma because $\mathrm{Apo}(\mathrm{a})$ isoforms with high molecular weight are tightly bound and degrade more quickly through endoplasmic reticulum unlike Apo(a) isoforms with a lower molecular weight. Most genetic variations are due to mutations in the Kringle IV domain, the lower part is due to mutations in promoter region (pentanucleotid repetitions) and the coding region ( $93 \mathrm{C} / \mathrm{T}$ polymorphism). For example, mutations in Kringle IV-9 domain participate in the formation of disulphide bridge, which leads to decreased synthesis of $L p(a)$ and low levels of Lp(a) levels.

Despite the fact that the concentration of $L p(a)$ is under a strong genetic control and remains stable throughout life, some case control studies found that some exogenous factors can have a small but significant impact on the concentration of $L p(a)$ levels. Concentration of $L p(a)$ can be increased by fatty acids of marine origin as elaidic acid, orchiectomy and hypothyroidism. Reducing effect of $L p(a)$ concentration has palm oil, polyunsaturated fatty acid and hormones replacement therapy in postmenopausal women (de Bruin et al., 1993; Soma et al., 1993; Hermann et al., 1995; Tholstrup et al., 1995; Marcovina et al., 1996).

Because of its similarity with plasminogen, $\operatorname{Lp}(\mathrm{a})$ shows thrombogenic and atherogenic properties and may disturb the balance between procoagulant and anticoagulant, anti-inflammatory and proinflammatory, vasodilatation and vasoconstriction and properties of the endothelium. $L p(a)$ can disrupt the function of endothelium and that makes this molecule not only a link between atherosclerosis and thrombosis, but also a link between endothelial dysfunction and these two processes. There are more mechanisms of atherogenicity and thrombogenicity of $L p(a)$. 


\section{Role of $\mathbf{L p}(\mathbf{a})$ in atherogenesis}

Atherosclerosis is a complex process that includes the following events in the arterial wall: deposition of plasma lipoproteins, proliferation of cellular elements, and inflammatory response. The progression of atherosclerosis is conducted in several steps, starting from the foam cell formation to complex atherosclerotic plaque composed of a core rich in lipids and necrotic cell debris, covered with fibrous cap. Lp(a) stimulates atherogenesis by several mechanisms: induction of inflammatory cytokines and adhesion molecules on the surface of vascular endothelial cells, transport of oxidized phospholipids, chemoattraction, inhibition the synthesis of nitrogen monoxide, vascular remodelling, and proliferation of smooth-muscle cells.

Induction of inflammatory cytokines and adhesion molecules on the surface of endothelial cells

The first event in the arterial wall in atherogenesis is the adhesion of mononuclear cells to the endothelium mediated by increased expression of adhesion molecules from endothelial cells as vascular cell adhesion protein-1 (VCAM-1), intercellular adhesion molecule-1 (ICAM-1), E-selectin, P-selectin. LP(a) increase the expression of adhesion molecules (VCAM-1, ICAM-1, E-selectin and P-selectin) on the surface of vascular endothelial cells, which initiate atherosclerotic changes in the vessel wall. $L P(a)$ induces increased expression of interleukin-8 (IL-8), interleukin-1 $\beta$ (IL-1 $\beta)$, tumour necrosis factor- $\alpha$ (TNF- $\alpha$ ) in macrophages, cytokines - mediators in inflammation process of atherosclerosis (Beisiegel et al., 1990; Linton et al., 2000; Deb and Caplice, 2004).

\section{Chemotaxis}

LP(a) stimulates the secretion of monocyte chemotactic protein (MCP) by endothelial cells which causes chemotaxis of monocytes and their migration through the endothelial barrier. MCP is a potent chemoattractant for monocytes and a key cytokine in the pathogenesis of atherosclerosis. $\operatorname{Lp}(\mathrm{a})$ also activate the inflammatory transcription factor - nuclear factor $\mathrm{kB}$ leading to the recruitment of inflammatory cells along the arterial wall (Syrovets et al., 1997).

Oxidation of Apo(a), transport of oxidized phospholipids and inhibition of nitrogen monoxide synthase

Apo(a) is a subject to oxidation such LDL. The mechanisms by which $\operatorname{Lp}(\mathrm{a})$ accelerates these disorders are not fully understood, but the oxidized phospholipids present on apolipoprotein(a) might have an important role. Lp(a) is the major carrier of oxidized phospholipids in human plasma, and interventions that lower plasma $L p(a)$ levels also reduce the oxidized phospholipid concentration in plasma (Boffa and Koschinsky, 2019). Oxidized form of Apo(a) facilitates the binding of $L p(a)$ for macrophage scavenger receptor, triggering the formation of foam cells. Oxidized form of $L p(a)$ inhibits vasodilatation, stimulates the production 
of plasminogen activator inhibitor-1 (PAI-1) by vascular endothelial cells and stimulates the production of superoxide radicals - all these things make oxidized $L_{p}(a)$ more atherogenic than native Lp(a) molecule (Riis Hansen et al., 1994). Inhibition of nitric oxide synthase by $L p(a)$ leads to reduction of the concentration of nitrogen monoxide (NO). The reduced concentration of $\mathrm{NO}$ leads to oxidative stress and progression of atherosclerotic process, recognizing antiatherogenic role of $\mathrm{NO}$ as inhibition of $\mathrm{T}$-cell and smooth-muscle proliferation, neutrophil adhesion, platelet activation, and reduction of endothelial permeability. LP(a) initiates activation of matrix metalloproteinases MMP-2 and MMP-9. Low concentrations of $\operatorname{Lp}(\mathrm{a})$ levels have anti-inflammatory action, binding and removing oxidized phospholipids from the circulation, despite high concentrations of $L p(a)$ levels leading to excessive accumulation of oxidized phospholipids in the wall of blood vessels actuate the atherosclerotic progression (Bergmark et al., 2008). Lp(a) reduces the activation of latent transforming growth factor- $\beta$ (TGF- $\beta$ ), which shows a number of cellular effects, such as inhibition of smooth-muscle proliferation and migration, inhibition of expression of adhesion molecules on the surface of endothelial cells antiatherogenic actions. In the absence of TGF- $\beta$, cytokines can induce smoothmuscle proliferation and migration, thus the progression of atherosclerotic lesions (Kojima et al., 1991).

Proliferation of smooth-muscle cells, vascular remodelling and endothelial dysfunction Atherosclerotic plaques contain $L_{p}(a)$ proportional to the concentration of $L_{p}(a)$ levels, unlike normal arterial walls. Plasminogen lysine-binding sites of Apo(a) are probably very important in anchoring the $L p(a)$ in the extracellular matrix of the arterial wall. It has been proved that mutations of lysine binding sites reduce the affinity of $\operatorname{Lp}(\mathrm{a})$ in the artery wall. Apo(a) binds to several extracellular matrix proteins such as fibrin and defensins that are released by neutrophils during the

\section{Table 2 - Atherogenic mechanisms of lipoprotein(a)}

\begin{tabular}{l}
\hline Induction of inflammatory cytokines IL-8, IL-1 $\beta$ and TNF- $\alpha$ \\
\hline Increased expression of adhesion molecules on the surface of endothelial cells VCAM-1, \\
ICAM-1, E-selectin and P-selectin \\
\hline Increased secretion of MCP and activation of nuclear factor kB with subsequent monocyte \\
chemotaxis \\
\hline Oxidation of Apo(a) and formation of high atherogenic particles with LDL \\
\hline Increased transport of oxidized phospholipids in the blood vessel wall \\
\hline Reduced production of nitrogen monoxide with subsequent vasoconstriction \\
\hline Reduced activation of latent transforming growth factor- $\beta$ (TGF- $\beta$ ) with subsequent \\
smooth-muscle proliferation \\
\hline Increased endothelial permeability through rearrangement of the cytoskeleton
\end{tabular}

Labudovic D.; Kostovska I.; Tosheska Trajkovska K.; Cekovska S.; Brezovska Kavrakova J.; Topuzovska S. 
inflammatory process (Bdeir et al., 1999). Lp(a) interacts with $\beta 2$-integrin Mac-1, which promotes adhesion of monocytes and their transendothelial migration (Sotiriou et al., 2006). Recent experimental studies shown that Apo(a) perform the rearrangement of actin cytoskeleton through increased phosphorylation of myosin light chains by Rho/Rho kinase-dependent signalling pathway (first intracellular signalling path in endothelial cells mediated by $L p(a)$ ), leading to increased contraction and permeability of endothelial cells. This leads to impaired receptormediated vasodilation and the endothelial dysfunction. Overall proatherogenic role for this action of $L_{p}(a)$ has a lysine binding site of Kringle IV type 10 (Riches and Porter, 2012; Riches et al., 2013). Apo(a) induce expression of $\beta$-catenin with consequent increased cyclooxygenase-2 (COX-2) expression and prostaglandin E2 (PGE2) secretion, key events in inflammation and vascular remodelling (Dubé et al., 2012). Proteoglycans, as decorin-synthesized by vascular endothelial cells, play an important role in the retention of $L p(a)$ along the arterial wall (Klezovitch et al., 1998). In Table 2 are summarized the atherogenic mechanisms of $L p(a)$.

\section{Role of $\mathrm{Lp}(\mathrm{a})$ in thrombogenesis}

Lp(a) participate in thrombogenesis through several mechanisms: platelet aggregation and activation, inhibition of tissue factor pathway inhibitor (TFPI), decreased production of plasmin and increased expression of plasminogen activator inhibitor-1 (PAI-1).

Aggregation and activation of platelets

$\mathrm{Lp}(\mathrm{a})$ and $\mathrm{Apo}(\mathrm{a})$ initiate activation of platelets by thrombin receptor-activated hexapeptide (TRAP) and platelet activating factor (PAF). Lp(a) has ability for specifically binding to platelet activating factor - acetyl hydrolase (PAF-AH) and thus inhibits PAF. $L P(a)$ has antiaggregatory effect mediated by its interaction with the integrin allb $\beta 3$, which normally binds to fibrinogen to induce platelet aggregation. Apo(a) binds to fibrin in a complex which inhibits the activation of plasminogen (Tsironis et al., 2004).

Inhibition of tissue factor pathway inhibitor (TFPI) and reduced production of plasmin Many cells have receptors for plasminogen, including endothelial cells and platelets. $L p(a)$ and $A p o(a)$ inhibit the binding of plasminogen to annexin (plasminogen receptor on the surface of platelets and endothelial cells), thereby preventing the activation of plasminogen to plasmin by the action of tissue factor pathway activation $(t-P A)$. Simultaneously, $L p(a)$ interferes with the binding sites of $t-P A$ on the surface of endothelial cells. $L p(a)$ reduces the production of t-PA by the endothelial cells (Kat, 2002). This leads to an antifibrinolytic state. Antifibrinolytic effect of Lp(a) depends on the size of the molecular weight of $A p o(a)$ - those with lower molecular weight have greater antifibrinolytic effect. $L p(a)$ promotes thrombosis by binding and inhibiting the tissue factor pathway inhibitor (TFPI). 


\section{Table 3 - Thrombogenic mechanisms of lipoprotein(a)}

Inhibition of platelet activation factor (PAF)

Inhibition of tissue factor pathway inhibitor (TFPI) and plasmin reduced production

Increased expression of plasminogen activator inhibitor-1 (PAI-1)

Increased expression of plasminogen activator inhibitor-1 (PAI-1)

Lp(a) stimulates the production of PAI-1 by endothelial cells in blood vessels by protein kinase $C(P K C)$-dependent mechanism. $L p(a)$ interacts with other proteins, such as prothrombotic $\alpha 2$-macroglobulin (plasmin inhibitor) and serine proteinase inhibitor A1 (SERPINA1) which is t-PA inhibitor. Transforming growth factor- $\beta$ (TGF- $\beta$ ) is plasmin substrate. Reduced synthesis of plasmin by $\operatorname{Lp}(\mathrm{a})$ leads to inhibition of TGF- $\beta$ and progression of atherosclerosis (Etingin et al., 1991). In Table 3 are summarized the thrombogenic mechanisms of $L p(a)$.

\section{Conclusion}

In this paper we reviewed the published literature data on atherogenic and thrombogenic role of $L p(a)$ in development of cardiovascular diseases. $L p(a)$ has a wide range of functional effects in development of cardiovascular diseases, such as modulation of platelet aggregation, reduced fibrinolysis, recruitment of inflammatory cells, vascular remodelling. Atherogenic and simultaneously thrombogenic function of $L p(a)$ makes this molecule very powerful in development of atherosclerosis and cardiovascular diseases. $L p(a)$ act through multiple pathogenic protein molecules and receptors that makes it impossible to find a single therapeutic target, but requires action at multiple levels in the mechanism of pathogenic action of $L p(a)$. More extensive trials are required in signalling pathways and molecular mechanisms in the action of $L p(a)$. That will provide in the near future possibility to identify sensitive therapeutic target in reducing $L p(a)$ levels.

\section{References}

Anderson, T. J., Grégoire, J., Pearson, G. J., Barry, A. R., Couture, P., Dawes, M., Francis, G. A., Genest, J. Jr., Grover, S., Gupta, M., Hegele, R. A., Lau, D. C., Leiter, L. A., Lonn, E., Mancini, G. B., McPherson, R., Ngui, D., Poirier, P., Sievenpiper, J. L., Stone, J. A., Thanassoulis, G., Ward, R. (2016) 2016 Canadian Cardiovascular Society Guidelines for the management of dyslipidemia for the prevention of cardiovascular disease in the adult. Can. J. Cardiol. 32(11), 1263-1282.

Bdeir, K., Cane, W., Canziani, G., Chaiken, I., Weisel, J., Koschinsky, M. L., Lawn, R. M., Bannerman, P. G., Sachais, B. S., Kuo, A., Hancock, M. A., Tomaszewski, J., Raghunath, P. N., Ganz, T., Higazi, A. A., Cines, D. B. (1999) Defensin promotes the binding of lipoprotein(a) to vascular matrix. Blood $\mathbf{9 4 ,}$ 2007-2019.

Beisiegel, U., Niendorf, A., Wolf, K., Reblin, T., Rath, M. (1990) Lipoprotein(a) in the arterial wall. Eur. Heart J. 11, 174-183.

Berg, K. (1963) A new serum type system in man: the Lp system. Acta Pathol. Microbiol. Scand. 59, 369-382. 
Bergmark, C., Dewan, A., Orsoni, A., Merki, E., Miller, E. R., Shin, M. J., Binder, C. J., Hörkkö, S., Krauss, R. M., Chapman, M. J., Witztum, J. L., Tsimikas, S. (2008) A novel function of lipoprotein [a] as a preferential carrier of oxidized phospholipids in human plasma. J. Lipid Res. 49, 2230-2239.

Boffa, M. B., Koschinsky, M. L. (2016) Lipoprotein (a): Truly a direct prothrombotic factor in cardiovascular disease? J. Lipid Res. 57, 745-757.

Boffa, M. B., Koschinsky, M. L. (2019) Oxidized phospholipids as a unifying theory for lipoprotein(a) and cardiovascular disease. Nat. Rev. Cardiol. 16, 305-318.

Catapano, A. L., Graham, I., De Backer, G., Wiklund, O., Chapman, M. J., Drexel, H., Hoes, A. W., Jennings, C. S., Landmesser, U., Pedersen, T. R., Reiner, Ž., Riccardi, G., Taskinen, M. R., Tokgozoglu, L., Verschuren, W. M. M., Vlachopoulos, C., Wood, D. A., Zamorano, J. L., Cooney, M. T.; ESC Scientific Document Group (2016) 2016 ESC/EAS Guidelines for the management of dyslipidaemias. Eur. Heart J. 37(39), 2999-3058.

Danesh, J., Collins, R., Peto, R. (2000) Lipoprotein(a) and coronary heart disease. Meta-analysis of prospective studies. Circulation 102(10), 1082-1085.

Deb, A., Caplice, N. M. (2004) Lipoprotein(a): New insights into mechanisms of atherogenesis and thrombosis. Clin. Cardiol. 27(5), 258-264.

de Bruin, T. W., van Barlingen, H., van Linde-Sibenius Trip, M., van Vuurst de Vries, A. R., Akveld, M. J., Erkelens, D. W. (1993) Lipoprotein(a) and apolipoprotein B plasma concentrations in hypothyroid, euthyroid and hyperthyroid subjects. J. Clin. Endocrinol. Metab. 76, 121-126.

Dubé, J. B., Boffa, M. B., Hegele, R. A., Koschinsky, M. (2012) Lipoprotein(a): More interesting than ever after 50 years. Curr. Opin. Lipidol. 23, 133-140.

Etingin, O. R., Hajjar, D. P., Hajjar, K. A., Harpel, P. C., Nachman, R. L. (1991) Lipoprotein(a) regulates plasminogen activator inhibitor-1 expression in endothelial cells. A potential mechanism in thrombogenesis. J. Biol. Chem. 266(4), 2459-2465.

Frank, S., Durovic, S., Kostner, K., Kostner, G. M. (1995) Inhibitors for the in vitro assembly of Lp(a). Arterioscler. Thromb. Vasc. Biol. 15, 1774-1780.

Graham, I., Atar, D., Borch-Johnsen, K., Boysen, G., Burell, G., Cifkova, R., Dallongeville, J., De Backer, G., Ebrahim, S., Gjelsvik, B., Herrmann-Lingen, C., Hoes, A., Humphries, S., Knapton, M., Perk, J., Priori, S. G., Pyorala, K., Reiner, Z., Ruilope, L., Sans-Menendez, S., Scholte op Reimer, W., Weissberg, P., Wood, D., Yarnell, J., Zamorano, J. L., Walma, E., Fitzgerald, T., Cooney, M. T., Dudina, A.; European Society of Cardiology (ESC) Committee for Practice Guidelines (CPG) (2007) European guidelines on cardiovascular disease prevention in clinical practice: executive summary: Fourth Joint Task Force of the European Society of Cardiology and Other Societies on Cardiovascular Disease Prevention in Clinical Practice (Constituted by representatives of nine societies and by invited experts). Eur. Heart J. 28, 2375-2414.

Grundy, S. M., Cleeman, J. I., Merz, C. N., Brewer, H. B. Jr., Clark, L. T., Hunninghake, D. B., Pasternak, R. C., Smith, S. C. Jr., Stone, N. J.; National Heart, Lung, and Blood Institute; American College of Cardiology Foundation; American Heart Association (2004) Implications of recent clinical trials for the National Cholesterol Education Program Adult Treatment Panel III guidelines. Arterioscler. Thromb. Vasc. Biol. 24, e149-e161.

Hermann, W., Biermann, J., Kostner, G. M. (1995) Comparison of effects of N-3 to N-6 fatty acids on serum levels of lipoprotein(a) in patients with coronary artery disease. Am. J. Cardiol. 76, 459-462.

Hrzenjak, A., Frank, S., Wo, X., Zhou, Y., Van Berkel, T., Kostner, G. M. (2003) Galactose-specific asialoglycoprotein receptor is involved in lipoprotein (a) catabolism. Biochem. J. 376, 765-771.

Kat, H. (2002) Regulation of functions of vascular wall cells by tissue factor pathway inhibitor: basic and clinical aspects. Arterioscler. Thromb. Vasc. Biol. 22, 539-548.

Lp(a) - Link between Atherosclerosis and Thrombosis 
Khan, T. Z., Hsu, L.-Y., Arai, A. E., Rhodes, S., Pottle, A., Wage, R., Gatehouse, P. D., Banya, W., Giri, S., Collins, P., Pennell, D. J., Barbir, M. (2017) Apheresis as novel treatment for refractory angina with raised lipoprotein(a): a randomized controlled cross-over trial. Eur. Heart J. 38, 1561-1569.

Klezovitch, O., Edelstein, C., Zhu, L., Scanu, A. M. (1998) Apolipoprotein(a) binds via its C-terminal domain to the protein core of the proteoglycan decorin. Implications for the retention of lipoprotein(a) in atherosclerotic lesions. J. Biol. Chem. 273, 23856-23865.

Kojima, S., Harpel, P. C., Rifkin, D. B. (1991) Lipoprotein(a) inhibits the generation of transforming growth factor $\beta$ : an endogenous inhibitor of smooth muscle cell migration. J. Cell Biol. 113(6), 1439-1445.

Kraft, H. G., Lingenhel, A., Raal, F. J., Hohenegger, M., Utermann, G. (2000) Lipoprotein(a) in homozygous familial hypercholesterolemia. Arterioscler. Thromb. Vasc. Biol. 20(2), 522-528.

Kronenberg, F., Steinmetz, A., Kostner, G. M., Dieplinger, H. (1996a) Lipoprotein(a) in health and disease. Clin. Lab. Sci. 33, 495-543.

Kronenberg, F., Utermann, G., Dieplinger, H. (1996b) Lipoprotein(a) in renal disease Am. J. Kidney Dis. 27, $1-25$.

Linton, M. R. F., Yancey, P. G., Davies, S. S., Jerome, W. G., Linton, E. F., Song, W. L., Doran, A. C., Vickers, K. C. (2000) The Role of Lipids and Lipoproteins in Atherosclerosis. MDText.com, Inc. Available at: https://www.ncbi.nlm.nih.gov/books/NBK343489/

Lippi, G., Targher, G. (2012) Optimal therapy for reduction of lipoprotein(a). J. Clin. Pharm. Ther. 37(1), 1-3.

Ma, K. L., Gong, T. K., Hu, Z. B., Zhang, Y., Wang, G. H., Liu, L., Chen, P. P., Lu, J., Lu, C. C., Liu, B. C. (2018) Lipoprotein(a) accelerated the progression of atherosclerosis in patients with end-stage renal disease. BMC Nephrol. 19(1), 192.

Malgaretti, N. F., Acquati, P. M., Magnaghi, P., Bruno, L., Pontoglio, M., Rocchi, M., Saccone, S., Della Valle, G., D'Urso, M., LePaslier, D. (1992) Characterization by yeast artificial chromosome cloning of the linked apolipoprotein(a) and plasminogen genes and identification of the apolipoprotein(a) 5' flanking region. Proc. Natl. Acad. Sci. U. S. A. 89(23), 11584-11588.

Marcovina, S. M., Lippi, G., Bagatell, C. J., Bremner, W. J. (1996) Testosterone-induced suppression of lipoprotein(a) in normal men: Relation to basal lipoprotein(a) level. Atherosclerosis 122, 89-95.

McCormick, S. P. A., Schneider, W. J. (2019) Lipoprotein(a) catabolism: a case of multiple receptors. Pathology 51(2), 155-164.

McLean, J. W., Tomlinson, J. E., Kuang, W. J., Eaton, D. L., Chen, E. Y., Fless, G. M., Scanu, A. M., Lawn, R. M. (1987) cDNA sequence of human apolipoprotein(a) is homologous to plasminogen. Nature 330(6144), 132-137.

Moriarty, P. M., Hemphill, L. (2016) Lipoprotein apheresis. Endocrinol. Metab. Clin. North Am. 45, 39-54.

Nordestgaard, B. G., Langsted, A. (2016) A lipoprotein(a) as a cause of cardiovascular disease: Insights from epidemiology, genetics, and biology. J. Lipid Res. 57(11), 1953-1975.

Nordestgaard, B. G., Chapman, M. J., Ray, K., Boren, J., Andreotti, F., Watts, G. F., Ginsberg, H., Amarenco, P., Catapano, A., Descamps, O. S., Fisher, E., Kovanen, P. T., Kuivenhoven, J. A., Lesnik, P., Masana, L.,

Reiner, Z., Taskinen, M. R., Tokgozoglu, L., Tybjaerg-Hansen, A. (2010) Lipoprotein(a) as a cardiovascular risk factor: current status. Eur. Heart J. 31, 2844-2853.

Puckey, L., Knight, B. (1999) Dietary and genetic interactions in the regulation of plasma lipoprotein(a). Curr.

Opin. Lipidol. 10, 35-40.

Reblin, T., Niemeier, A., Meyer, N., Willnow, T. E., Kronenberg, F., Dieplinger, H., Greten, H., Beisiegel, U. (1997) Cellular uptake of lipoprotein[a] by mouse embryonic fibroblasts via the LDL receptor and the LDL receptor-related protein. J. Lipid Res. 38(10), 2103-2110.

Reyes-Soffer, G., Ginsberg, H. N., Ramakrishnan, R. (2017) The metabolism of lipoprotein(a): an everevolving story. J. Lipid Res. 58, 1756-1764. 
Riches, K., Porter, K. E. (2012) Lipoprotein(a): cellular effects and molecular mechanisms. Cholesterol 2012, 923289.

Riches, K., Franklin, L., Maqbool, A., Peckham, M., Adams, M., Bond, J., Warburton, P., Feric, N. T., Koschinsky, M. L., O’Regan, D. J., Ball, S. G., Turner, N. A., Porter, K. E. (2013) Apolipoprotein(a) acts as a chemorepellent to human vascular smooth muscle cells via integrin $\alpha \mathrm{V} \beta 3$ and RhoA/ROCK-mediated mechanisms. Int. J. Biochem. Cell Biol. 45, 1776-1783.

Rifai, N., Ma, J., Sacks, F. M., Ridker, P. M., Hernandez, W. J., Stampfer, M. J., Marcovina, S. M. (2004) Apolipoprotein(a) size and lipoprotein(a) concentration and future risk of angina pectoris with evidence of severe coronary atherosclerosis in men. Clin. Chem. 50, 1364-1371.

Riis Hansen, P., Kharazmi, A., Jauhiainen, M., Ehnholm, C. (1994) Induction of oxygen free radical generation in human monocytes by lipoprotein(a). Eur. J. Clin. Invest. 24, 497-499.

Schmidt, K., Noureen, A., Kronenberg, F., Utermann, G. (2016) Structure, function, and genetics of lipoprotein(a). J. Lipid Res. 57, 1339-1359.

Soma, M. R., Osnago-Gadda, I., Paoletti, R., Fumagalli, R., Morrisett, J. D., Meschia, M., Crosignani, P. (1993) The lowering of lipoprotein[a] induced by estrogen plus progesterone replacement therapy in postmenopausal women. Arch. Intern. Med. 153, 1462-1468.

Sotiriou, S. N., Orlova, V. V., Al-Fakhri, N., Ihanus, E., Economopoulou, M., Isermann, B., Bdeir, K., Nawroth, P. P., Preissner, K. T., Gahmberg, C. G., Koschinsky, M. L., Chavakis, T. (2006) Lipoprotein(a) in atherosclerotic plaques recruits inflammatory cells through interaction with Mac-1 integrin. FASEB J. 20, 559-561.

Syrovets, T., Thillet, J., Chapman, M. J., Simmet, T. (1997) Lipoprotein(a) is a potent chemoattractant for human peripheral monocytes. Blood 90, 2027-2036.

Tholstrup, T., Markmann, P., Vessby, B., Sandstorm, B. (1995) Effects of fats high in individual saturated fatty acids on plasma lipoprotein(a) levels in young health men. J. Lipid Res. 36, 1447-1552.

Tsimikas, S. (2017) A test in context: Lipoprotein(a): Diagnosis, prognosis, controversies, and emerging therapies. J. Am. Coll. Cardiol. 69, 692-711.

Tsironis, L. D., Mitsios, J. V., Milionis, H. J., Elisaf, M., Tselepis, A. D. (2004) Effect of lipoprotein(a) on platelet activation induced by platelet-activating factor: role of apolipoprotein(a) and endogenous PAF-acetylhydrolase. Cardiovasc. Res. 63(1), 130-138.

van Capelleveen, J. C., van der Valk, F. M., Stroes, E. G. (2016) Current therapies for lowering lipoprotein(a). J. Lipid Res. 57(9), 1612-1618. 